\title{
TIPOS DE PENSAMENTO JUDAICO (IV).
}

\section{(Conclusão) .}

\section{FRITZ PINKUSS}

do Curso de Hebraico da Faculdade de Filosofia, Letras e Ciências Humanas da Universidade de São Paulo.

\section{CAPITULO VII.}

\section{EMANCIPAÇÃO, MODERNISMO E SECULARIZAÇAOO.}

Para o pensamento judaico termina a Idade Média em meados do século XVIII (1). O que é típico do espírito medieval, é o esforço da conservação; ele determina o pensamento a partir da época da conclusão do Talmude, a qual coincide com o começo da Idade Média; extende-se, pois, sobre um milênio. Houve muita literatura, em parte clássica, em todos os domínios do pensamento, porem sempre dedicada à preservação, explicação e aplicação.

$\mathrm{O}$ pensamento não se isolou de todo do meio ambiente, sempre tinha encontros com o mundo fora do guetto, mas ele se estreitava, no decorrer dos séculos, não por culpa própria, e sim por circunstâncias históricas. O Sefaradi (2) perdeu seu ímpeto intelectual da Idade-Média, e o Ashquenazi (3) sentiu as algemas físicas e, mais ainda, intelectuais, do guetto, e se tornou receoso acerca de qualquer diálogo (3a) .

Nestes meados do século XVIII surgem os fenômenos do modernismo, com os seguintes elementos:

1. - As ciências analíticas modernas criticam a autoridade medieval da religião;

(1). - Coincide com o começo da era moderna recentemente tambem assim fixada na história geral, enquanto antigamente o Renascimento determinava o fím da Idade Média.

(2). - Judeu oriundo da Península Ibérica.

(3). - Judeu de origem alemã.

(3a). - Convem fazer uma observação acerca dos MARRANOS (Cristãos Novos), intelectuais, eles não representam uma camada de pensamento judaico original, novo, mas:

"Contra o fundo de uma idade que produziu um número de desenvolvimentos destacadamente 'modernos' no Judaismo, eles apresentam-se como os primeiros judeus modernos. Em virtude dos anos que cada um tinha vivido na 
2. - Uma nova filosofia clama pela Tolerância, - John Locke, e Hugo Grotius, com o seu jus gentium. Da Tolerância o caminho está em princípio aberto para os Direitos do Homem;

3. - O Deísmo cria uma separação entre ética e religião, e nega a personalidade da Divindade.

Isolados em séculos, não por culpa própria, os judeus com seu modo de pensar não estão preparados para se tornarem europeus, serem emancipados, no sentido da Tolerância. Eles enfrentam o problema de serem jogados da sociedade fechada do guetto para a sociedade aberta. No guetto era facil, era natural, ser judeu; fora tornou-se muito mais dificil.

Os poucos intelectuais judeus querem antecipar-se ao processo lento da emancipação. A tolerância não thes pode recusar o direito de, como seres humanos, serem iguais aos demais. O Deismo esvazia a religião positiva, de sorte que é um passo somente sair do Judaismo para a religião oficial: o Cristianismo, no seu aspecto protestante prussiano. Berlim torna-se o centro desta tendência. Um fenômeno até então inaudito: Religião e Pensamento Tradicional entram em descrédito e caem no abandono, considerados como impedimento à obtenção da emancipação. - David Friedlaender, de Berlim, explica à sua filha o passo para o batismo, declarando que o Cristianismo é a forma atualizada de crer em Deus, uma vez que a "religião natural" (ética) constitui o mesmo substrato em todos os credos positivos. Por que etão sofrer como judia, em vez de se emancipar como cristã? (4). Os intelectuais europeus exigem como consequente aplicação da Tolerância, a emancipação do indivíduo judaico. Assim a luta pela

Península, estes antigos Marranos (retornados ao Judaismo, como por exemplo Spinoza) constituiram o primeiro grupo consideravel de judeus europeus que tinham as suas mais extensas e diretas experiências completamente fora da comunidade orgânica e do universo espiritual da tradição normativa judaicas. E mais ainda, como cristãos nominais na Espanha e em Portugal, tinham gozado de acesso integral às fontes do estudo ocidental teológico, filosofico, cientifico". - conf. Yosef Haim Yerushalmi: From Spanish Court to Italian Ghetto: Isaac Cardoso, A Study in Seventeenth Century Marranism and Jewish Apologetics. Columbia University Press, 1972, cit. conf. Commentary, New York, vol. 54, julho 1972, pág. 94.

(4). - PINKUSS (Fritz), Israel Povo dos Milênios, cap. IX. Pelo Congresso de Viena (1815) é revogada de forma inédita a emancipação. Napoleão decreta prazo de adaptação, apresenta um Sanhedrim, assembléia de notáveis, para lhes impor as perguntas que alarmam. 
emancipação sai em parte da intelectualidade judia e tambem, muito mais ainda, da intelectualidade européia. A atitude oficial dos Estados varia entre a concessão da emancipação do indivíduo, não da coletividade, e a reação nutrida pelo argumento de que as massas judaicas não estão preparadas para a entrada na sociedade européia, marginalizadas que eram em costumes, língua (yidish) e educação cívica. Nasce o anti-semitismo moderno na sociedade européia: Com as energias intelectuais reprimidas em séculos, estas explodem agora: o judeu emancipado abraça as profissões liberais, provocando inveja e ódio, como new-comer talentoso, no meio da civilização européia (5).

As tentativas judaicas de emancipação partem do Ocidente europeu, especialmente da Alemanha prussiana. Moisés Mendelssohn, homem culto e modesto (6), amigo dos iluministas europeus, como Lessing, é envolvido na luta literária; vê a necessidade de adaptação do judeu "medieval" na sociedade aberta e cristã, porem sem perder a sua identidade judaica. Com esta finalidade cria escolas, e traduz a Bíblia para o alemão, usando letras hebraicas para transmitir aos judeus que falavam o yidish, o conhecimento do idioma do meio-ambiente. Houve rabinos que excomungaram esta tradução, mas os tempos passaram sobre eles. Um lado da tarefa foi este: adaptar o judeu. O outro foi reinterpretar e modernizar o judaismo (7) medievalizado. Ele adota, e veremos mais detalhes adiante (8), a filoso:ia do Deismo, declarando que o. Judaismo baseia toda a sua ética na Lei Natural, filosófica, fundamento de todas as crenças, enquanto Torá é somente Lei Revelada para determinar os costumes, as festas, o cerimonial. Com a religião tradicional que ele ainda próprio observara, esvaziada na sua substância, gerações posteriores de intelectuais subidos na escalada social, trocaram diante das dificuldades de obter a emancipação, seu credo judaico pelo credo "oficial", o Protestantismo. Assim fracassou umc tentativa honesta, com graves perdas pa:a a comunidade judaica, com uma profunda confusão acerca da "religião positiva" e a dissolução da substância tradicional. Entre os teóricos da emancipação houve outros mais radicais ainda como: Saul Ascher (9) para o qual, em seu radicalismo e em sua superficialidade, a

(5). - Ibidem.

(6). - PINKUSS (Fritz), Moses Mendelssohn's Philosophie, Fulda, 1928 (Goerres-Gesellschaft). Philos. Jahrbuch. cipação.

(7). - Veja o capítulo subsequente: Consequências da Época da Eman-

(8) . - Parte da Filosofia Moderna.

(9). - PINKUSS (Fritz), Saul Ascher, Ein Unbekannter Theoretiker des Judentums und der Emancipation em "Zeitschrift für Jüdische Familienforschung", Frankfurt, 1934. 
"meta do Judaismo é educar o judeu como bom cidadăo, sendo 'o estilo prussiano o ideal".
\end{abstract}

No Leste europeu não havia Tolerância. Existem alí no meio judaico dois caminhos de pensamento: o tradicionalista, o Hassidismo, e o novo: a $H A S K A L A$, iluminismo. Os impulsos gerados em Berlim tinham revolucionado o pensamento dos intelectuais judeus do leste: o judeu deve tornar-se europeu. A personalidade catalizadora é Nahman Krochmal, com o seu lema: - sê no teu íntimo judeu, e fora sê europeu. - $\mathrm{O}$ movimento da Haskalá conduz ao renascimento do Hebraico como língua; no intuito de transmitir a Europa ao judeu oriental, traduzem-se para o hebraico obras da literatura européia, deste modo acessíveis ao guetto. Krochmal escreve um livro Guia dos Desnorteados da Epoca, lembrando de propósito o título Guia dos Desnorteados de Maimônides. A Haskalá não deixou de significar, com suas idéias modernistas, um desafio aos rabinos tradicionalistas, os quais reagiram de modo veemente.

O "Mendelssohn" do Leste, Isaac Beer Levinson, recomendando o estudo simultâneo do Russo e do Hebraico, estimula a publicística do mesmo e cria a primeira revista moderna neste idioma, o HAME' ASSEF, Colecionador, com material literário traduzido do meio europeu. Ele preconiza que a Haskalá, com a entrada cultural do judeu na Europa, não fere a tradição religiosa do mesmo. Sua voz não foi entendida e houve ásperas discussões e rígidas separações entre os MASKILIM (progressistas do Iluminismo, Haskalá) e os Tradicionalistas.

No Ocidente lutava-se pela integração na sociedade européia; na Rússia, ela não foi possivel. Surgem então movimentos no Leste, com carater messianista: o renascimento do nacionalismo judaico, em primeira fase o Sionismo Sentimental (HOVEVE SION); e em resposta ao antisemitismo, o Sionismo estimula os ânimos em toda a Europa pelo segundo tipo: o Político (HESS, TEODORO HERZL), - e o terceiro: o Sionismo Cultural de Ahad Ha'Am. Outros judeus da Rússia concentram-se em movimentos operários modernos, socialistas - o BUND (associação), ele é arreligioso, mas nacionalista, e cria uma rica literatura em yidish (Mendele Mocher Sefarim, Sholem Aleichem). Este Bund, levado pelas vítimas dos pogroms czaristas para os E.E.U.U., alí organisa os primeiros sindicatos, no fim do século passado e no início do século XX.

Na Europa Ocidental apresentam-se de forma nítida quatro fenômenos do pensamento "novo" do judeu: 
a. - A Ciência Moderna do Judaismo (Wissenschaft des Ju-
dentums);
b. - A Reforma Teológica;
c. - A Moderna Filosofia do Judaismo;
d. - O Nacionalismo - Sionismo. a). - A CIENCIA MODERNA DO JUDAISMO.

Ela é conhecida pelo seu título alemão, por ter a sua origem na Alemanha em luta pela emancipação, e de lá se expande para a Itália, França, Inglaterra e E.E.U.U., tendo hoje seu centro na Universidade Hebraica de Jerusalem. Até os tempos modernos, Ciência do Judaismo significava Torá, Talmude-Torá, Estudo do Ensinamento, explicação e interpretação da Lei. Agora, a Wissenschaft des $J u$ dentums tem meta completamente diferente: pesquisa histórico-filológica das fontes. Procura linhas evolutivas para fins de comprovação de que o judaismo possui tendências e possibilidades inatas de atualização. No momento em que o pensamento pré-emancipatório ainda era escolástico, autoritário, aceitou a Ciência do Judaismo o desafio para ele entrar na sociedade aberta, comprovando que o Judaismo jamais foi estático no seu pensamento. Estão no início deste empreendimento duas obras: As Alocuções Devocionais dos Judeus de Leopoldo Zunz, exemplo do método filológico, que pesquiza o espírito evolutivo, e mais ainda: Abraham Geiger, Texto Original e Traduções da Bíblia, em que o autor comprova que no decorrer da história, o texto não somente foi traduzido, mas que cada tradução significava evolução do pensamento. A "evolução" é a idéia magna que domina esta especialidade.

Como resposta às guerras napoleônicas têm início o novo nacionalismo e o romantismo, na Europa; tambem o enciclopedismo francês ainda vigorava. Na Universidade de Berlim nasce a filosofia do Idealismo de Hegel, com a sua dialética histórica. Este sistema hegeliano dá estímulo, outlet e método, para a Ciência do Judaismo (10). O seu âmbito ficou, todavia, restrito às camadas acadêmicas. A Wissenschaft des Judentums não teve contato com o pensamento das massas, as quais praticamente a ignoravam, mas exerceu influência decisiva sobre o Judaismo vivo, como fenômeno cultural. Citamos:

(10). - Preleção de Ismar Elbogen na "Hochschule fuer die Wissenschaft des Judentums", Berlim, 1928 (citado pelas anotações feitas pelo autor).

ELBOGEN (Ismar), A Century of Jewish Life, Jewish Publication Society of America, Philadelphia, 1945.

GRAETZ (Heinrich), History of the Jews, Jewish Publication Society of America, Philadelphia, vol. V. Cap. XVI, 1946. 
"Judaismo apresenta-se em forma dupla: primeiro os documentos da história e da literatura, em um volume extenso de escritos, e segundo: como um princípio ainda vivo, reconhecido por milhões de pessoas dispersas no mundo... cada ciência não só exerce a sua influência sobre outras ciências, mas tambem sobre a vida. Isto facilmente pode ser comprovado ser justo com respeito à Ciência do Judaismo" (11).

Ismar Elbogen (12) torna-se mais explícito: sem um relacionanamento com o Judaismo vivo, a Wissenschaft des Judentums iria perder a sua razão de existir. Isto significa que os homens mais qualificados para definir o conceito da Ciência do Judaismo, enfaticamente preconizam a importância de seu relacionamento com o Judaismo vivo como uma conditio sine qua non.

Sem duvida foi a Ciência do Judaismo quem forneceu as bases para o pensamento filosófico, e mais ainda, teológico, do judaismo moderno. Recomendamos ao leitor procurar detalhes, - pois aqui tentamos somente dar linhas gerais do pensamento, - em descrições históricas (13).

A Historiografia Judaica que, até os tempos modernos, era simples cronografia com tendências teológicas e martiriologia, torna-se ciência no sentido analítico, baseada em fontes e em sua elucidação crítica. As primeiras tentativas neste sentido são o artigo extenso sobre "Judaismo" na Enciclopédia de Ersch e Gruber, e os três volumes da História do Judaismo e das suas Seitas, título um pouco ingênuo, de Marcus Jost (14). Heinrich Graetz é o primeiro que emprega vasto aparelho crítico e método de pesquisador nos doze volumes da sua História Mundial do Judaismo, ainda hoje, devido à pesquisa minuciosa das fontes, um livro básico do ramo. A partir de então, há uma cadeia ininterrupta de historiadores do povo judeu, do judaismo, de temas especializados da sua história, sendo o mais recente: Salo W.. Baron, A History of Social and Religious Life of the Jewish People (15).

(11). - Cit. Conf. Alexander Guttman, Hochschule Retrospektive, em "Central Conference of American Rabbis Journal", New York, 1972, pg. 79. WOLF (Immanuel), On the Concept of a Science of Judaism, 1822, and ELBOGEN, Ismar - Zum Begriff Wissenschaft des Judentums em Annual of the HOCHSCHULE, Berlim, 1932, pg. 34.

(12). - lbidem.

(13). - PINKUSS (Fritz), Israel Povo dos Milênios, capítulos, XIX, XX.

(14). - LEIPZIG, ed. Dorffling e Franke, 1858, 3 vol. Povo...

(15). - Recomendamos a bibliografia anexa a Fritz Pinkuss, Israel 
Wissenschaft des Judentums foi o título que Leopoldo Zunz deu a este empreendimento, que teve origem na fracassada "Associação de Cultura Judaica" em Berlim, entre cujos membros havia Heinrich Heine, o poeta judeu-alemão. A Ciência do Judaismo sobreviveu à sua celula mater logo desaparecida. Interessante é a motivação que criou a primeira obra deste ramo: houve tentativas de introduzir prédicas em alemão em serviços religiosos modernizados em Berlim, Hamburgo e Seesen. Estas foram proibidas por parte das autoridades alemãs com o motivo de serem imitações do culto cristão. Em resposta a esta proibição, escreveu Zunz As Alocuções Devocionais dos Judeus, obra mater em que foi comprovado que em todos os tempos normais na história do povo se utilizava o idioma do meio-ambiente para a alocução litúrgica. Esta pesquisa ilustrou a grande meta de Zunz: não é suficiente emancipar o judeu como indivíduo, mas emancipar o Judaismo e faze-lo conhecido. Por motivos políticos e de convicção, não se falava mais do Povo Judaico, mas do. indivíduo, uma vez que a Emancipação no sentido da Tolerância conhecia e se referia ao Homem como indivíduo somente. Assim se interpretou no ato da emancipação na França:

"Ao judeu como indivíduo tudo, como povo nada".

A partir de Zunz criou-se toda uma escola, com o centro em Berlim. Todos da Wissenschaft des Judentums escreveram em alemão, no intento de chegar à inteligentsia européia; mais tarde em outros paises, na língua do meio ambiente. Destacam-se seis temas básicos:

1. - História Geral, Econômica, Social, Religiosa e Cultural dos judeus;

2. - História Biográfica;

3. - Estudo Crítico-Filológico da literatura judaica, secular e religiosa;

4. - Pesquisa acerca do nivel cultural e da flexibilidade do judaismo tradicional;

5. - Bibliografia Judaica;

6. - Filosofia moderna do judaismo.

O tema, segundo o qual a simples preservação das formas tradicionais do Judaismo não responderia à problemática da atualidade de então, constituiu-se no leitmotiv da Wissenschaft des Judentums e das diversas tentativas empreendidas pela Reforma, no sentido de criar um diálogo contínuo com a realidade. 


\section{b). - A REFORMA TEOLOGICA.}

Na primeira fase, a vasta maioria dos rabinos permaneceu alheia ou adversária à Reforma; "leigos" foram os que se encarregaram da mesma. Esta primeira tentativa foi superficial: a reforma restringiu-se ao culto e às suas formas: introdução do órgão, prédica no vernáculo, concentração da liturgia, tentativa de equiparação dos sexos, introdução de uma disciplina cívica rígida no meio dos que assistiam aos serviços religiosos. A Reforma Teológica permanecia quase que ausente por completo, nesta fase que se ocupou somente com as formas cerimoniais.

$\mathrm{Na}$ segunda fase, entra a Ciência do Judaismo. Leopold Zunz tinha comprovado a possibilidade e a permissibilidade da reformulação dos conceitos teológicos. Abraham Geiger, destacado discípulo de Zunz, empenha-se na mesma. O Texto Original e as Traduções da Bíblia estabelece que, junto com as versões, tinha havido adaptações e modificações dos conceitos. Isto significa que o judaismo é evolutivo (16). Assim se abandona o método tradicional da "explicação escolástica", só possivel muitas vezes, através da alegoria em relação às partes difíceis dos textos.

As decisivas consequências da interpretação evolutiva são:

1. - A revolta contra a autoridade indiscutivel da Tradição e do passado, a favor da reformulação e da reforma que são comprovadas como compatíveis com a Tradição;

2. - A atitude legalista, baseada na Torá, cede em favor da concepção profética e fortemente universalista;

3. - O conceito de Revelação do Sinai é separado do seu contexto fundamentalista. De outro lado, ela e declarada como fato não isolado, repetindo-se a manifestação da Divindade em processo contínuo, alem daquele hic et hoc, até a atualidade e em todo o futuro; por exemplo: a revelação através do progresso das ciências;

4. - O serviço de Deus - alem do culto reformado - é basicamente a atitude ética, a qual se projeta acima de ritual e cerimônias (característica dos Profetas Clássicos);

5. - $O$ aspecto ético-universalista do Judaismo nega a existência atual de um povo israelita, transformando-se o judaismo em uma espécie de igreja;

6. - Em vez do Messias pessoal é postulada a Era Messiânica futura, de paz, justiça, fraternidade universais, e espera-

(16). - No sentido hegeliano. 
da como fim de um processo evolutivo da humanidade. Este conceito respira o ar de otimismo do liberalismo clássico;

7. - A dispersão de Israel consta do plano providencial divino, por ter o judaismo a missão explícita, como Servo de Deus, de testemunhar na Humanidade o Deus Único e a Sua Etica.

Os fatos históricos mais destacados deste movimento reformista são os seguintes: Samuel Holdheim e Abraham Geiger tiram como os primeiros, todas as consequências da nova doutrina. Todos os elementos nacionais são declarados inválidos na atualidade, tendo vigorado somente durante a existência do Estado Judaico. Transformam o Judaismo em uma espécie de igreja; abolem as tradicionais lembranças da distinção entre o povo e seus sacerdotes. Introduzem o vernáculo, o alemão, como língua de rezas. Abolem as orações pelo retorno ao Sion; o Shabat é transferido para o dia de descanso público, o domingo. Holdheim, em Berlim, é o pai da Reforma.

Ela não encontrou solo fertil na Europa Continental, mas tornou-se movimento no mundo anglo-saxônico, em especial, nos Estados Unidos depois da Independência, onde ela foi aclamada pela coerência com o desejo americano de rejuvenescimento. A justiça deve constatar que a Reforma é hoje mais conservadora, com o Shabat outra vez no sábado, com a reintrodução parcial do hebraico; em todo caso ela conseguiu manter as massas americanizadas da classe burguesa abastada, ao Judaismo; ela aceita hoje o conceito do "povo judaico".

O encontro com o mundo moderno achou tambem outras soluções, às vezes em caminho inverso. Em vez do racionalismo ético da Reforma, surge no Leste um pietismo com traços fortemente moralistas; seu mestre carismático é Israel Salanter. - A séria reação à Reforma - todavia - gera a fundação da NEO-ORTODOXIA por Samson Rafael Hirsch. Ele parte do ponto de vista oposto: nega o princípio evolutivo-liberal e declara que tudo o que foi uma vez, em qualquer lugar, decretado, estabelecido, é Torá e, por se-lo, é imutavel e inabolivel. E o mais consequente tradicionalista; prega a aplicação do verbo mishnáico da Etica dos Pais: Torá junto com a vida cotidiana (Torá im Derekh-Eretz). Por meio da interpretação homilética elucida as tradições. Surgiu da parte da Neo-Ortodoxia uma crítica ferrenha aos modernistas, a qual chegou ao ponto de criar comunidades sectárias, como em Hamburgo, Francfort, Berlim, etc. e de declarar a Reforma um "outro" credo.

Não tardaram a chegar atitudes intermediárias entre os dois extremos: 
a) . - A orientação do Liberalismo europeu. Ele não chegou a criar um sistema novo de tradição, aproximou-se mais ou menos à plataforma teológica da Reforma moderada. O característico é o liberalismo geral do século passado, aplicado no sentido de que sempre de novo se apela ao indivíduo para cada vez de novo, e dian'e de cada problema de consciência religioso-ética, este aja com seu senso de responsabilidade, no intuito de criar uma síntese viavel e viva entre tradição $\mathrm{e}$ atualidade.

b) . - Outro grande esforço para encontrar meio-caminho e harmonização entre os extremos da neo-ortodoxia e do modernismo, é o que se chama JUDAISMO CONSERVADOR. Teve sua primeira idealização com Zacarias Frankel de Breslau. Ele mantem em princípio a Halaká, LEI, modificando-a o menos possivel e tentando reconhece-la o mais possivel; chama-se Judaismo Histórico Positivo. A ele deve-se a criação do primeiro seminário teológico acadêmico de Breslau, arquétipo para as correspondentes acadêmicas estabelecidas pelas demais denominações judaicas. O conservadorismo não é tanto uma plataforma sistemática, lógica, mas o apelo à consciência "histórica" do povo, no sentido sentimental de responsabilidade perante a tradição em um mundo transformado.

Enquanto na Europa Continental dominavam todas as nuances de Liberalismo, Ortodoxia, Conservadorismo, nos Estados Unidos houve um tremendo desenvolvimento estrutural da Reforma, a partir de Isaac M. Wise, do Conservadorismo com Salomon Schechter, e da Ortodoxia. Recentemente se agrega a isto o movimento da Neo-Ortodoxia Hassídica do Rav de LUBAVITSCH.

Em Israel, o pensamento religioso está em fase anterior ao KULTURKAMPF, exercendo uma ortodoxia medieval, estritamente legalista, de influência retardadora. Não há dúvidas de que o modernismo está para se organizar e representar no futuro uma força espiritual nova no Pais.

A primeira e única escola de pensamento religioso, genuinamente americana, é o RECONSTRUCTIONISM de Mordechai M. Kaplan. Ele parte do princípio são, de unir todas as identificações judaicas, de todos os domínios, religioso-ético, social, artístico, cultural, étnico, etc., sejam elas indeferentes à religião ou não. Define o Judaismo como uma "Civilização com Denominador Religioso". Esta formulação permite ao judeu cônscio, mas alheio ao pensamento tradicional, encontrar seu lugar dentro desta "civilização". 
Kaplan

"declara o Judaismo uma entidade histórica, com essências nacionais, sociais e éticas. Por óbvios motivos históricos, esta essência articulou-se no passado em formas religiosas. Com o enfraquecimento da religião na civilização moderna, tornou-se necessária e legítima uma re-interpretação secular do pensamento judaico e da sua essência histórica. Muito da cultura nacional judaica contempo ânea baseia-se nesta premissa" (17).

Das mais radicais é a sua definição da Divindade, praticamente deista, naturalista: Deus é a força que me orienta a me realizar. Neste sistema fica problemático o lugar da reza: a quem será ela dirigida? Será que ela se transformou em simples meditação?

Existe no mundo atual, em grande parte difundido, o Pensamento Secu'arista, especialmente tambem em Israel. O pensamento judaico não rejeita esta atitude como "herética". O Reconstrucionismo é uma tentativa de resposta. Um outro esforço neste sentido data do grande rabino A. F. Kook, chefe espiritual de Israel (falecido em 1935). Ele

"interpretou o Judaismo secular ou socialista, como uma etapa do processo necessariamente dialético para a concretização da vocação e do destino judaico" (18).

\section{c). - A FILOSOFIA MODERNA.}

"A parede divisora que separou o Judaismo da vida intelectual e social dos povos europeus, caiu só em meados do século XVIII. Até então os grandes movimentos da vida intelectual da Europa somente de forma superficial tocaram o mundo judaico... A verdadeira junção, legítima e perfeita, com a cultura européia, traz o Iluminismo do século XVIII, no sentido social e intelectual. Isto de modo destacado pode ser dito da filosofia. Os interesses filosóficos tinham encontrado sua satisfação no cultivo das tradições filosóficas da Idade Média judaica...".

"Tinha o Judaismo na Idade Média e na era nova incipiente o seu círculo cultural, o qual, repousando em bases religiosas, abrangia toda a vida intelectual..., agora a cultura moderna européia separou toda a vida intelectual dos seus laços religiosos, destruindo assim as bases da unidade cultural tradicional... Até

(17). - WERBLOWSKY, Judaism, pg. 45.

(18). - Ibidem. 
os problemas gerais da filosofia, de agora em diante, são tratados independentes das suas relações com o judaismo, e tambem da parte daqueles pensadores que se sabe em perfeito acordo com a religião judaica. Estes pensadores judaicos, que assim agem, seguem a tendência largamente aplicada à filosofia moderna, de comprovar a verdade da religião indeperdentemente de qualquer relação com uma determinada confissão religiosa...".

"Para o Judaismo resultam consequêrcias essencialmente diferèntes do que para o Cristianismo. $O$ ensi cementos religiosos básicos do Judaismo são na sua formulação e definição em todo o caso, idênticos às idéias gerais da religião monoteista. Suas c'enças não ultrapassam estas idéias, como no dogma cristão, e não contrastam com elas. - De um lado, ficou o judaismo poupado dos conflitos originários do choque entre a crítica racional e o dogma cristão, - de outro lado, todavia, correu o perigo de ser identificado pura e simplesmente com o sistema destas idéias e perder o seu conteudo específico. Sob o domínio da Religião da Razão. seja no entender do Iluminismo, seja no sentido da fé racional ética de Kant, sempre de novo se tem feito esta identificação, com - que parecia tornar-se desnecessátia uma descrição filosófica e fundamentação do judaismo. Só paulatinamente passou uma análise profunda para alẹ́m desta simplificação... e reconheceu a necessidade de uma fundação filosófica autônoma do judaismo".

"Assim se explica que nos tempos modernos não se chegou a uma evolução contínua da filosofia judaica, como na Idade Média, e o que segue a partir de então, é descriçăo de uma sequência de vultos individuais" (19).

Apesar dos fenômenos individuais, podemos ressaltar, não escolas, mas tipos de pensamento filosófico, apresentados nos seus mais destacados representantes:

Moses Mendelssohn - Além do seu lugar destacado na luta pela emancipação (20), é filósofo da religião.

"Tambem como tal ele não é filósofo do Judaismo. Das suas obras principais sobre filosofia da religião, no Phaidon e nas $H o$ ras Matinais ele justifica a idéia de Imortalidade e a Fé em Deus, não com ensinamentos da religião judaica, mas como produto da fé racional e da metafísica geral. Elas foram escritas para a Ale-

(19), - GUTTMAN (Julius), Philosophie, pg. 301-302.

(20). - PINKUSS (Fritz), Moses Mendelssohn's Philosophie, GörresGesellschaft, Fulda, 1928. 
manha erudita da sua época, e procuravam e acharam nesse meio a sua repercussão. O seu conteúdo, todavia, está em mais perfeita harmonia com o ensinamento judaico" (21).

Sua filosofia geral é a tentativa inicial da harmonização do realismo inglês com o racionalismo continental, nos anos que precederam - Kantismo (22). Enquanto sua filosofia da religião não contrasta com o judaismo, ela não é filosofia judaica; sua repercussão foi de valor moral, apresentando-se o judeu ainda não politicamente emancipado, mas na altura da civilização e da inteligência da Europa.

\section{O IDEALISMO HEGELIANO.}

Salomon Formstecher define o Judaismo com a "história do desabrochamento de uma idéia" (account of the unfolding of an idea). Esta idéia do monoteísmo ético é tão difícil para o mundo pagão, que Cristianismo e Islamismo são duas agências missionárias do espírito da Bíblia do Velho Testamento.

Nahman Krochmal - Assim como Hegel considerava o Estado Prussiano como ponto de apogeu da evolução, Krochmal interpretava o Judaismo como processo evolutivo-dialético, com o ponto alto na Wissenschaft des Judentums, em sua auto-interpretação. O ideal de cada nação e civilização, segundo Krochmal, reflete o interesse dominante que move a mesma: guerra, comércio, direito, arte, filosofia, etc... A nação cresce, desabrocha, declina, desaparece. Somente a existência de Israel é diferente: por ser consagrado ao Espírito Absoluto Eterno ele é AM OLAM, Povo da Eternidade. Há uma sequência inacabavel de ciclos históricos no seu caminho através dos tempos, não por causa de talentos ou méritos destacados, mas pela "Obra da Providência Divina".

\section{OS NEO-KANTIANOS.}

Hermann Cohen - fundador da escola Neo-Kantista de Marburgo, escreve uma filosofia da religião em bases racionalistas, identificando o pensamento judaico com a "religião da razão", na sua obra intitulada: Religião da Razão nas Fontes do Judaismo. Estabelece o nexo entre o mundo externo-lógico da "razão pura" e o mundo "interno" da convicção ética da "vontade pura". - Deus lhe é o "garante da Lei ética" no mundo. A religião difere somente no "acesso" a respeito da filosofia, mas com ética idêntica. O "ritual" inteiro tem a sua

(21). - Ver capítulo que trata da Emancipação e GUTTMAN (Julius), pg. 304 .

(22). - Ver FRITZ PINKUSS, MOSES MENDELSSOHNS PHILOSOPHIE (Tese Doutoramento, Fulda, 1928). 
razão de existir, para santificar a vida e as suas tarefas. - $\mathrm{O}$ homem, com profundo sentimento religioso, que era Cohen, aliás fortemente contrário ao sionismo moderno incipiente, considera o pensamento judaico como "proclamador" dos valores éticos proféticos universais e universalistas. Fortemente recusando o Panteísmo, postula a "idade áurea" para o futuro - e não a procura no passado - e nela orienta a ética da "vontade pura", filosófica, estabelecendo identidade de conteúdo da mesma com a ética judaico-religiosa.

Léo Baeck - pesquisa na sua obra máxima, A Essência do Judaismo (23), os valores ético-espirituais do pensamento judaico, definido de forma clássica, pelo seu Monoteismo Et co. Concede lugar secundário ao cerimonial, porem lhe dá o seu valor básico para a "Conservação da Comunidade" (parte final da obra). Distingue entre "religião clássica", baseada no Ordenamento, e "religião romântica", cujo arquétipo the é o Cristianismo (24). Preconiza o aspecto duplo da Revelação: nacional no sentido histórico, e universal pelo seu conteudo, como o Decálogo e o "amor ao próximo". Em vez da fé confidente no contínuo progresso, como o liberalismo clássico, ressalta o carater árduo e trágico do destino judaico, postulando com voz alta a liberdade do indivíduo contra o absolutismo (prussiano) do Estado e da religião estatal.

\section{OS EXISTENCIALISTAS.}

Martim Buber - não é somente o filósofo do Pensamento Judaico per se no seu aspecto de ensinamento social, mas dirige seu olhar para a situação existencialista do Encontro do indivíduo com seu Deus. Procura os grandes exemplos nas personalidades carismá-

(23) . - Originalmente esboçada como resposta à Essência do Cristianismo de Harnack, Berlim, no começo do século. Foi depois, em um número grande de ediçóes, ampliada e constituiu durante décadas a obra mestra do pensamento judaico. Baseamo-nos na última edição espanhola, Buenos Aires, Ed. Paidos, 1964.

(24). - BAECK (Leo), Judaism and Christianity, Jewish Publication Society of America, Philadelphia, 1958, pg. 189. "No judaísmo, o Sagrado é concebido como um ordenamento, por isto uma obrigação que cai ao moio deste mundo, o qual é racional e ético; no Cristianismo, o Sagrado é essencialmente um mistério, por isto o "receptáculo da fé", é transcendente e trans-ético" (cit. conf. Jacob Bernard Agus, Jewish Self-Definition, "Central Conference of American Rabbis Journal", New York, 1972, pg. 11) AGUS não concorda de todo com esta distinção feita por Baeck, achando-se no conceito judaico do "Povo" traços românticos e místicos, como no etnicismo sagrado de Juda Ha'Levi ou no Zohar; - e de outro lado, no Cristianismo, a Patrística reintroduziu o racionalismo do Helenismo e o moralismo do Judaismo. Ele refere-se tambem à influência do LOGOS nos ensinamentos de Jesus nos Evangelhos Sinóticos., pg. 12. 
ticas do Hassidísmo, cujas parábolas edita, e da Bíblia que traduz junto com Franz Rosenzweig, um uma nova versão ao alemão. Aplica nesta tradução a sua teoria acertada, segundo a qual, como ler e ouvir são no semítico expressos pelo mesmo verbo QARÁ, o texto deve ser ouvido, lido com voz alta. Ele não trata tanto dos conceitos teológico-filosóficos acerca de Deus, mas do confronto existencial do indivíduo com seu Deus. Prega a relação do Eu-Tu (em vez da relação do $I c h-E s$ ), o Tu dirigido a Deus e o Tu dirigido ao Homem. Neste sentido revive as experiências do povo judaico. Sua influência foi maior e mais intensa sobre a teologia cristã existencialista, especialmente protestante, do que sobre o próprio pensamento judaico.

O teólogo e filósofo protestante Paul Tillich afirmou que

"Martim Buber tem tríplice e profunda significação para $\circ$ Protestantismo: por causa de sua interpretação existencial da religiño profética; - por causa da sua redescoberta do misticismo como elemento inerente à religião profética; e finalmente, por sua compreensão da relação entre a religião profética e a cultura, especialmente no campo social e político" (25).

Franz Rosenzweig - na sua "Estrela da Redenção", como BAAL TESHUVÁ (26), que é, ensina o afastamento da especulação meramente acadêmica e do jogo do intelecto, em favor da experiência religiosa. Estabelece a experiência tripartite acerca de Deus: - na Criação, - na Revelação, - na Salvação. Encara dois caminhos da verdade: o Judaismo e o Cristianismo. Hoje é o redescoberto nos EE.UU. pelo pensamento existencialista, seja judaico, seja cristão.

Will Herberg - é o primeiro pensador existencialista do Judaismo nos EE.UU. Aplica, no sentido clássico da escola, o "Salto para a Fé" (leap of faith) de Kierkegaard, para assegurar à religião judaica o seu lugar em face da existência humana atual, como criatura que sente o Ensinamento, como contraditório à situação em que a humanidade hoje vive. Sua obra magna é Judaism and Modern Man.

Abraham Joshua Heshel - descendente de sete gerações de Hassidim, introduz a neo-mística no existencionalismo religioso. Postula "experimentar" o Infalivel, Deus Ontológico. Inverte as posições neste sentido ontológico: não é o Homem quem procura Deus, é Deus quem procura o Homem (26a). Escreveu antes da sua recente morte,

(25). - MOTTA (Jorge Cesar), o Que Nos Une, na revista "Encontro", do Conselho de Fraternidade Cristä-Judaica, São Paulo, 1972, n⿳ 10, pg. 10. (26) . - "Aquele que pratica o RETORNO depois de ter-se afastado". (26a).-Deus precisa do Homem. 
grande número de livros, os mais destacados são: Os Profetas, Deus à Procura do Homem.

Mordechai M. Kaplan (27) - com o seu Reconstrucionismo, está com seu pensamento entre a reforma teológica e a filosofia. Sua doutrina foi descrita no capítulo que trata da Reforma teológica.

Uma influência temporária exerceu o livro existencialista de Joshua Loth Libman, Peace of Mind (Paz da Alma) que lembra as idéias de Schleyermacher, experimentar Deus pelo sentimento. Dirige-se com métodos psicanalíticos ao homem "desnorteado", apresentando-lhe perante a sua ANGST (angústia) o fator consolador, acalmante: o encontro religoso. O livro, infiuenciado pela teoria de Schleyermacher, apela mais para o sentimento religioso geral, do que para uma denominação religiosa certa .

\section{d). - O NACIONALISMO}

Em consequência, primeiro da situação precária, e depois da Segunda Guerra Mundial, catastrófica, para a maior parte do povo judeu, abandonam-se os conceitos meramente universalistas, em favor do redescobrimento vivo do nacionalismo; ressurge do fundo da alma judaica o sonho messiânico (28). Assim havemos de entender o Sionismo em todas as suas fases e variações. $\mathrm{Na}$ sua energia e dinâmica, apesar de parecer secularizado pela atuação política, não seria compreensivel, sem se ter em mente que estas tendências e tensões messiânicas ficaram no longo caminho da história conservadas no subconsciente e na convicção religiosa, irrompendo de tempos em tempos, em resposta e desafio aos cataclismos existenciais. Os fatos que se deram desde a Segunda Guerra Mundial modificaram profundamente a imagem do judeu. Somente uma história do Sionismo conseguirá esclarecer as suas características.

(27). - Ver o capítulo acerca da Reforma.

(28). - Que jamais tinha sido de todo abandonado, ficando vivo, especialmente na liturgia, no ritual, - e nos movimentos sionistas, desde o início do Sionismo Moderno. 